\title{
Perceptual and Neural Response to Affective Tactile Texture Stimulation in Adults with Autism Spectrum Disorders
}

\author{
Carissa J. Cascio, Estephan J. Moana-Filho, Steve Guest, Mary Beth Nebel, Jonathan \\ Weisner, Grace T. Baranek, and Gregory K. Essick \\ From the Center for Neurosensory Disorders, University of North Carolina School of Dentistry, \\ Chapel Hill, NC (E.J.M.-F., S.G., J.W., G.K.E.); Department of Allied Health Sciences, Division of \\ Occupational Science and Occupational Therapy, University of North Carolina, Chapel Hill, NC \\ (G.T.B.); Department of Psychiatry, Vanderbilt University, Nashville, TN (C.J.C.); Vanderbilt \\ Kennedy Center for Research on Human Development, Nashville, TN (C.J.C.); Kennedy Krieger \\ Institute, Johns Hopkins University, Baltimore, MD (M.B.N.)
}

\begin{abstract}
Autism spectrum disorders (ASD) are associated with differences in sensory sensitivity and affective response to sensory stimuli, the neural basis of which is still largely unknown. We used psychophysics and functional magnetic resonance imaging (fMRI) to investigate responses to somatosensory stimulation with three textured surfaces that spanned a range of roughness and pleasantness in a sample of adults with ASD and a control group. While psychophysical ratings of roughness and pleasantness were largely similar across the two groups, the ASD group gave pleasant and unpleasant textures more extreme average ratings than did controls. In addition, their ratings for a neutral texture were more variable than controls, indicating they are less consistent in evaluating a stimulus that is affectively ambiguous. Changes in brain blood oxygenation leveldependent (BOLD) signal in response to stimulation with these textures differed substantially between the groups, with the ASD group exhibiting diminished responses compared to the control group, particularly for pleasant and neutral textures. For the most unpleasant texture, the ASD group exhibited greater BOLD response than controls in affective somatosensory processing areas such as the posterior cingulate cortex and the insula. The amplitude of response in the insula in response to the unpleasant texture was positively correlated with social impairment as measured by the Autism Diagnostic Interview-Revised (ADI-R). These results suggest that people with ASD tend to show diminished response to pleasant and neutral stimuli, and exaggerated limbic responses to unpleasant stimuli, which may contribute to diminished social reward associated with touch, perpetuating social withdrawal, and aberrant social development.
\end{abstract}

\section{Keywords}

touch; fMRI; sensory; adults; psychophysics; affective

\section{Introduction}

Autism spectrum disorders (ASD) are a group of pervasive developmental disorders, characterized by impairments in social interaction, communication, and patterns of rigid or

\footnotetext{
(C) 2012 International Society for Autism Research, Wiley Periodicals, Inc.

Address for correspondence and reprints: Carissa Cascio, Vanderbilt University Department of Psychiatry, 1601 23rd Ave South, Suite 3057, Nashville, TN. carissa.cascio@vanderbilt.edu.

None of the authors have conflicts of interest to declare.
} 
repetitive behavior that are apparent in the first few years of life [APA, 2000]. Both unusually positive and unusually negative affective reactions to basic sensory stimuli are prominent features in Kanner's original description [Kanner, 1943], and sensory symptoms affect a substantial majority (70-80\%) of individuals with autism [Baranek, David, Poe, Stone, \& Watson, 2006; Ben-Sasson et al., 2008; Dawson \& Watling, 2000; Kientz \& Dunn, 1997]. Sensory processing differences in infancy are associated with increased risk for ASD [Baranek, 1999; Damiano et al., 2011; Rogers, 2009], and burgeoning evidence supports the claim that basic sensory processing differences contribute to the deficits in more complex social, cognitive, and behavioral symptoms that define ASD [Boyd et al., 2010; Foss-Feig et al., 2012; Hilton et al., 2010; Jones, Quigney, \& Huws, 2003; Watson et al., 2012].

The vast majority of the literature on sensory differences in ASD derives from parent or selfreport rather than direct observation in the laboratory. These studies are rich in ecological validity, but there is a need for more studies using direct observation and psychophysics to characterize sensory symptoms in a more controlled and objective way. There has been an increase in the application of these approaches to the somatosensory system in ASD in recent years [Blakemore et al., 2006; Cascio et al., 2008; Güçlü, Tanidir, Mukaddes, \& Unal, 2007; Tommerdahl, Tannan, Cascio, Baranek, \& Whitsel, 2007].

Aberrant tactile processing is among the most commonly reported sensory symptoms in ASD [Rogers, Hepburn, \& Wehner, 2003; Tomcheck \& Dunn, 2007], and shows strong association with core features [Hilton et al., 2010; Lane, Young, Baker, \& Angley, 2010]. Paradoxically, it is also much less widely studied than its counterparts in the auditory and visual systems. This bias may reflect the relevance of hearing and vision for verbal communication, but it is important to consider the role of touch in preverbal sociocommunicative development that lays the groundwork for communication in infancy. Touch is central in building the foundation for social interaction [Harlow \& Harlow, 1962], bonding [Field, 2001; Montagu, 1986; Myers, 1984], novelty exploration [Harlow \& Harlow, 1962], and secure attachment [Main \& Stadtman, 1981; Weiss, Wilson, Hertenstein, $\&$ Campos, 2000], while lack of maternal tactile contact early in infancy is associated with repetitive behaviors that are characteristic of ASD [Harlow \& Harlow, 1962]. Touch, therefore plays a crucial role in early development of social [Morrison, Löken, \& Olausson, 2010], communication [Hertenstein, Verkamp, Kerestes, \& Homes, 2006], and other behaviors that are affected in ASD.

Touch information is conveyed from the skin to the brain via afferent fibers that innervate distinct classes of mechanoreceptors. Large myelinated afferents (A $\beta$-fibers) convey tactile sensation resulting from mechanical skin deformation, and densely innervate the fingertips and lips, reflecting their importance in discriminative touch. Unmyelinated afferents (Cfibers) convey pain and temperature information, and a separate class of C-fibers known as C-touch (CT) afferents responds selectively to slow, stroking touch, [Olausson et al., 2002] and innervate the face and hairy skin but are absent from the glabrous skin of the palm [Vallbo, Olausson, \& Wessberg, 1999].

Because of their response properties and absence from the fingertips, the CT afferent system is widely believed to be specialized for affective, rather than discriminative touch [Löken, Wessberg, Morrison, McGlone, \& Olausson, 2009; McGlone, Vallbo, Olausson, Loke, \& Wessberg, 2007]. Functional magnetic resonance imaging (fMRI) studies suggest that these fibers project selectively to insular cortex, without activation of primary somatosensory cortex (SI) to which A- $\beta$ fibers project [Olausson et al., 2008].

Prior psychophysical studies of discriminative touch comparing groups with ASD to controls have yielded mixed results, with reports of enhanced vibrotactile localization 
[Tommerdahl et al., 2007] and enhanced vibrotactile detection [Blakemore et al., 2006;

Cascio et al., 2008], which show specificity for either certain frequencies or certain somatic locations. At the same time, studies failed to find group differences in vibrotactile detection [Güçlü et al., 2007] and light touch detection [Cascio et al., 2008] thresholds. Failure of an adapting stimulus to improve spatial localization of stimuli has been interpreted as a lack of normal cortical inhibitory processes [Tommerdahl et al., 2007]. In striking contrast to the numerous fMRI studies of the visual system in ASD, to our knowledge, no studies have yet been published using fMRI to examine the neural basis of altered touch perception in ASD. Thus, there is much to learn about the brain's response to touch in ASD, although available evidence from magnetoencephalography suggests aberrant somatotopic mapping [Coskun et al., 2009].

While discriminative touch may not be reliably abnormal in ASD, the emotional aspects of touch are more consistently reported to be affected in ASD [Cascio et al., 2008; Güçlü et al., 2007]. Aberrant responses in ASD may be selective for this kind of touch and neural differences may be related to the $\mathrm{CT}$ afferent system. As such, differences measured by fMRI may be more prominent in higher order association areas such as secondary somatosensory cortex (SII), insula, or parietal somatosensory association areas than in primary SI.

Thus, we sought to replicate and extend previous findings [Cascio et al., 2008], focusing on a subset of stimuli that are relevant for affective touch: gentle stroking of the skin by an experimenter with a variety of textured surfaces with a range of perceived roughness and pleasantness based on prior psychophysical studies in nonclinical populations [Essick et al., 2010; Guest et al., 2011]. We investigated the perceived roughness, perceived pleasantness, and the neural response to these textures in parallel psychophysical and fMRI paradigms.

\section{Materials and Methods}

\section{Participants}

Adults with a diagnosis of ASD were recruited through a large university-based research registry. A comparison group matched for age and gender was also recruited through community advertisements. All participants gave informed consent for participation in the protocol, which was approved by the Institutional Review Board of the University. Cognitive ability was measured for all participants using the Wechsler Abbreviated Scales of Intelligence [WASI, Wechsler, 2003], and a full-scale IQ of at least 70 was required for inclusion in the study. Individuals in the ASD group were administered the Module 4 Autism Diagnostic Observation Schedule [ADOS, Lord, Rutter, DiLavore, \& Risi, 1999] by a research-reliable assessor; a confirmatory ADOS score above the cutoff for ASD was required for inclusion in the ASD group. For those participants who had a parent available, the Autism Diagnostic Interview (ADI-R, LeCouteur, Lord, \& Rutter, 2003) was also collected and used to further verify ASD diagnosis. Exclusion criteria were: history of medical conditions associated with autism such as Fragile X, tuberous sclerosis, and epilepsy, or MRI contraindications. The participants who were included in one or both experiments comprised of 18 individuals with ASD (all of whom had a Module 4 ADOS and 15 of whom had an ADI-R) and 17 without ASD. Analyses for each experiment include the 14 individuals with ASD and 16 controls that completed both sessions of the psychophysical experiment, and the 13 individuals with ASD and 14 controls that completed the fMRI experiment with translational and rotational head motion less than $3 \mathrm{~mm}$ or 3 degrees in any direction. The overlap (participants who completed both experiments) was ten participants in the ASD group and 13 in the control group. Group differences in age, IQ, and gender were not significant for the psychophysics group (Age: $t(28)=-1.27, P=0.214$, IQ: $t(28)=$ $-0.59, P=0.561$, gender: $\left.\chi^{2}(1)=1.2, P=0.467\right)$ nor for the fMRI group (Age: $\mathrm{t}(25)=$ 
$-0.56, P=0.58$, IQ: $t(25)=-0.72, P=0.48$, gender: $\left.\chi^{2}(1)=1.1, P=0.481\right)$. Participant characteristics are summarized in Table 1 .

\section{Psychophysical Roughness and Pleasantness Ratings}

In each session, the participant was administered five trials for each of three textures: a plastic mesh material, a burlap fabric, and a soft cosmetic brush. These three textures were chosen to represent a range of expected perceived pleasantness; previous studies have shown that in typical adults, the plastic mesh is usually perceived as somewhat unpleasant, the burlap fabric as neutral, and the cosmetic brush as pleasant [Essick et al., 2010], and that generally smooth stimuli are perceived as more pleasant than rough stimuli [Guest et al., 2009]. Each participant returned for a separate validation session on a second day.

The mesh and burlap covered the $3.75 \mathrm{~cm}$-wide block of foam on a foam paintbrush, and all three textures were administered by a trained experimenter manually stroking the textures proximo-distally along a $5 \mathrm{~cm}$ length of the dorsal forearm at an approximate rate of $5 \mathrm{~cm} / \mathrm{s}$. During a session, five trials were administered for each texture in randomized order. A screen shielded the participant's view of the site of stimulation. On each trial, after receiving stimulation by a texture, participants were asked to rate the texture for (a) roughness and (b) pleasantness, using a computer-based (15.4" laptop display) visual analog scale. The leftmost end of the scale was labeled as " $-100 \%$ rough" or " $-100 \%$ unpleasant," and the rightmost end of the scale labeled as " $100 \%$ smooth" or " $100 \%$ pleasant," as applicable. The midpoint of the scale was marked with a vertical line but was unlabeled. Ratings were made by moving a cursor on the screen using mouse, touchpad, or keyboard as preferred by the participant, with the participant finally accepting their rating via mouse click.

The average rating for each session was calculated and entered into separate linear mixed models in SPSS (version 18, Chicago, IL, USA), for pleasantness and roughness with texture, session, group, and trial as fixed effects. Main effects and all two and three-way interactions were assessed.

\section{fMRI}

A basic block design was employed using the same three textures and a baseline rest condition with no stimulation. Two runs (6 min each) were acquired with the three textures presented in pseudorandom blocks of 30 seconds each, alternating each texture block with a rest block of the same duration. During stimulation blocks, the experimenter continuously stroked the textures proximo-distally along the dorsal surface of the right forearm, with a moderate force and a speed of approximately $5 \mathrm{~cm} / \mathrm{s}$, covering approximately $8 \mathrm{~cm}$ per stroke, and jittering the location of stimulation by a few millimeters on each stroke to minimize receptor fatigue. Participants were instructed to lie still and attend to the brushing. During rest blocks, participants were instructed to relax and lie still, and no tactile stimulation was administered.

Images were acquired on a Siemens (Erlangen, Germany) 3 Tesla Allegra head-only MRI scanner. High-resolution anatomical images were acquired with a T1-weighted MPRAGE sequence $\left(160\right.$ axial slices, voxel size $=1 \times 1 \times 1 \mathrm{~mm}^{3}$, TR $=1700 \mathrm{~ms}, \mathrm{FOV}=192 \times 256$ $\mathrm{mm}^{2}$ ). Functional images were acquired using a T2*-weighted EPI sequence (50 axial slices, voxel size $=3 \times 3 \times 3 \mathrm{~mm}, \mathrm{TR}=3 \mathrm{~s}, \mathrm{FOV}=64 \times 64 \mathrm{~mm}^{2}$, interleaved acquisition).

\section{fMRI Analysis}

Images were analyzed using SPM5 running in Matlab 7.4.0 (R2007a) (http:// www.fil.ion.ucl.ac.uk/spm/). Functional images in both runs were realigned to the first volume and re-sliced, and translational and rotational motion of less than $3 \mathrm{~mm}$ and 3 
degrees, respectively, was verified using the output of the realignment step. Next, all realigned functional volumes were warped to a standard Montreal Neurological Institute (MNI) template brain for group comparison. Functional images were smoothed with a Gaussian kernel of 5 mm FWHM.

First-level analysis was specified for each participant using the general linear model design matrix, modeled using the canonical hemodynamic response function (HRF). The robust weighted least squares [rWLS, Diedrichsen \& Shadmehr, 2005] toolbox was used to inversely weight volumes according to their variance due to noise, thereby minimizing the contribution of volumes with motion spikes to the model. Each model was then estimated with the classical restricted maximum likelihood approach for spatially smoothed images.

Second-level (group) analysis was completed in two stages: (a) using one-sample $t$-tests to create contrasts between the three stimulation conditions and the baseline rest condition within groups; and (b) using two-sample $t$-tests to compare contrasts between the two groups.

A threshold of $Z>2.3$, a cluster size of at least 10 voxels, and an uncorrected $P$ value less than 0.005 [Lieberman \& Cunningham, 2009] were used to identify voxels with significant BOLD response in a whole-brain analysis. We created contrasts first in the groups separately to compare each texture with the baseline rest condition, and then created contrasts that examined the group differences for each of the three textures. Significant clusters were localized by converting the MNI coordinates to Talairach coordinates using the Matlab function mni2tal [Brett, Anton, Valabregue, \& Poline, 2002], and querying the Talairach coordinates using the Talairach atlas client [Lancaster et al., 1997, 2000] along with the Talairach and Tourneaux atlas [Talairach \& Tournoux, 1988] for confirmation. As an additional control for possible Type I error due to multiple comparisons, we performed 5000 P value simulations using AlphaSim (AFNI, Bethesda, Maryland, USA; http:// afni.nimh.nih.gov/pub/dist/doc/manual/AlphaSim.pdf) for each region containing a cluster that met the above threshold. Those clusters that met this family-wise error corrected $P$ value of 0.05 are highlighted with an asterisk in Tables 2 and 3.

\section{Results}

\section{Psychophysical Roughness and Pleasantness Assessment}

Roughness-The results of the model for roughness ratings yielded significant main effects of texture $\left(\mathrm{F}_{2,818}=954.8, P<.0001\right)$ and session $\left(\mathrm{F}_{1,818}=5.7, P=0.017\right)$. Significant two-way interactions were found for texture*session $\left(\mathrm{F}_{2,818}=6.4, P=0.002\right)$, group*texture $\left(\mathrm{F}_{2,818}=13.4, P<0.0001\right)$, and group*session $\left(\mathrm{F}_{2,818}=6.3, P=0.01\right)$.

Pleasantness-For pleasantness ratings, there was a significant main effect of texture $\left(\mathrm{F}_{2,818}=740.6, P<0.0001\right)$, session $\left(\mathrm{F}_{1,818}=19.4, P<0.0001\right)$, and a trend for an effect of trial (within-session) $(\mathrm{F}=2.3, P=0.06)$. Significant interactions were present for texture*session $\left(\mathrm{F}_{2,818}=7.4, P=0.001\right)$ and texture* $\operatorname{group}\left(\mathrm{F}_{2,818}=7.0, P=0.001\right)$; there was a trend for a significant interaction between trial and texture $\left(\mathrm{F}_{2,818}=1.8, P=0.07\right)$. The data from the psychophysical experiment are summarized in Figures 1 and 2.

The main effect of texture replicates prior findings that the brush tends to be rated as the least rough and the most pleasant, the mesh material the most rough and the least pleasant, with the burlap fabric intermediate between them. We also noted, consistent with previous work, strong and statistically significant correlations between smoothness and pleasantness ratings (Brush: ASD: $\mathrm{r}=0.820, \mathrm{p}<0.001$, Control: 0.634, $P=0.008$; Burlap: ASD: $\mathrm{r}=$ 0.912, $P<0.001$; Control: $\mathrm{r}=0.648, P=0.007$; Mesh: ASD: $\mathrm{r}=0.925, P<0.001$, Control: $\mathrm{r}$ 
$=0.932, P<0.001)$. When testing the correlation coefficients for differences between groups using the Fisher r-to-Z transformation, we found that the correlation between perceived smoothness and pleasantness was significantly greater in ASD than controls for burlap $(\mathrm{Z}=1.87$, $\mathrm{p}$ (one-tailed $)=0.03)$, but not for brush $(\mathrm{Z}=1.0, P=0.16)$ or mesh $(\mathrm{Z}=$ $-0.12, P=0.45)$.

The significant group*texture interactions for both pleasantness and roughness are reflected in the tendency for the ASD group to give more extreme ratings for the roughest and least pleasant stimulus, the plastic mesh (Fig. 1), although post hoc independent samples $t$-tests for mesh ratings fell short of statistical significance (Roughness (mesh): $t(28)=-1.2, P=$ $1.53, P=0.14$; Pleasantness (mesh): $t(28)=0.24$ ). Figure 1 also highlights that, for both sets of ratings, the variability in the ASD group was higher than the control group for the burlap texture. This was confirmed statistically with the Levene's test for equality of variances (Roughness (burlap): $\mathrm{F}(28)=7.6, P=0.01$; Pleasantness (burlap): $\mathrm{F}(28)=10.3, P=0.003$ ). This test was not significant for ratings of any other texture. The main effect of session, and interactions between session, and texture for both types of judgment, as well as between session and group for roughness judgments, are summarized in Figure 2.

\section{fMRI}

Within-Group Contrasts-For the soft brush stimulus compared to the baseline condition, the control group showed nine clusters that exceeded the extent and intensity thresholds described above. Laterality of clusters is described relative to stimulation (which was on the right forearm), thus ipsilateral refers to the right side and contralateral to the left. As expected, increases in BOLD signal were observed in contralateral SI and SII, inferior parietal lobule (IPL), as well as frontal and temporal regions (middle and inferior frontal gyri (MFG, IFG) and the middle temporal gyrus (MTG) ). In contrast, the ASD group only exhibited two clusters that exceeded a priori extent and intensity thresholds, one in contralateral SI and the other in contralateral superior frontal gyrus (SFG).

The neutral burlap material, which was rated on average as neither pleasant nor unpleasant, evoked a similar profile of signal increase in the control group, including contralateral SI, bilateral IPL, contralateral superior parietal lobule (SPL), ipsilateral MFG, and contralateral MTG. In contrast, the ASD group had no clusters that met threshold in response to stimulation with burlap.

For the mesh texture, the control group showed increased response in bilateral SI, contralateral primary motor cortex (MI), IPL, and MTG, and ipsilateral SII and IFG. The ASD group showed increased BOLD response to the mesh stimulus in contralateral SI, SII, precentral gyrus, and contralateral posterior insula, as well as ipsilateral MFG. The results for within-group contrasts are summarized in Table 2 and Figure 3.

Between-Groups Contrasts-Between-groups comparisons yielded significant areas of group difference in response to all three textures. Group contrasts are summarized in Table 3 and Figure 4.

For the soft brush stimulus, the control group had significantly greater BOLD response than the ASD group in ipsilateral SI, SPL, MFG, anterior cingulate, superior temporal gyrus (STG), and cerebellum, as well as contralateral cingulate cortex and bilateral precentral gyrus. The reverse contrast (ASD > control) revealed only a single significant cluster, in the left pulvinar nucleus of the thalamus.

For the burlap fabric, the control group had significantly greater BOLD response than the ASD group in bilateral SI (extending on the contralateral side inferiorly to include the 
paracentral lobule), MFG, ipsilateral IPL, IFG, and SFG, and ipsilateral precuneus and putamen. The reverse contrast (ASD > control) revealed no significant clusters.

For the mesh material, the control group showed significantly more activation in bilateral SI and medial frontal gyrus, as well as ipsilateral cingulate cortex, paracentral lobule, and SFG, and contralateral precentral gyrus, MFG, and caudate. The reverse contrast (ASD>Control) yielded clusters in the contralateral posterior insula, posterior cingulate, midbrain (red nucleus), and thalamus (pulvinar).

\section{Percent BOLD Signal Change in Insula and SI: Group Differences across Conditions and Correlation with Autism Diagnostic Variables-To investigate} possible relations between measures of social, communication, and repetitive behavior impairment and the group differences in BOLD response to these textures, we calculated mean percent change in the BOLD signal in two regions, primary somatosensory cortex (SI) and the insula, using the Marsbar [Brett et al., 2002] toolbox in SPM5. These were chosen primarily based on our two-sample results, but these choices were also supported by previous literature establishing SI as central to basic somatosensory processing, and the insula as specifically recruited for affective or socially relevant somatosensory stimuli [Olausson et al., 2002, 2008].

We hypothesized that overall group differences in BOLD response might be more prominent in affective processing regions such as the insula than in SI. Thus, we performed an analysis of variance (ANOVA) with mean signal change in each of these regions collapsed across conditions as the dependent variable but did not find a significant interaction between group and region $(\mathrm{F}(1150)=0.310, P=0.579)$.

We then performed twelve bivariate correlations between these values and the ADOS and ADI-R diagnostic algorithm subscores measuring social, communication, and repetitive behavior impairment. We found that in the left insula, a site which was more active in response to mesh in the ASD group than controls, the magnitude of the BOLD response to this texture significantly increased as ADI-R scores of social impairment increased $(\mathrm{r}=$ $0.643, P=0.03$, Fig. 5). Response in the left insula to the burlap texture also correlated with social impairment $(\mathrm{r}=0.640, P=0.03)$ and repetitive behaviors $(\mathrm{r}=0.619, P=0.04)$ as measured by the ADI-R, and response in the right insula correlated with repetitive behavior only $(\mathrm{r}=0.60, P=0.05)$. Given the exploratory nature of this study, $P$ values were uncorrected for multiple comparisons. No measures of autism symptomatology as measured by the ADI-R correlated with BOLD signal changes in SI, nor were any correlations between neural response and ADOS scores statistically significant.

\section{Discussion}

We found that individuals with high-functioning autism or Asperger's syndrome give similar average subjective ratings of the roughness and pleasantness of textured surfaces to their typical peers, although with more variability, particularly for the neutral burlap stimulus, and a slight tendency to find the least pleasant (mesh) stimulus rougher and less pleasant than did the control group (see Fig. 1). We also noted that, consistent with prior work [Guest et al., 2009, 2011], there is a negative relationship between perceived roughness and perceived pleasantness for these textures in both groups.

The increased variability in responses of the ASD group is consistent with a variety of studies demonstrating the profound heterogeneity of the disorder [for a review, see, Happe, Ronald, \& Plomin, 2006]. From clinical phenotype to neural signatures [Müller, Kleinhans, Kemmotsu, Pierce, \& Courchesne, 2003; Toal et al., 2010], heterogeneity in ASD is a 
pervasive challenge to autism research, prompting a growing emphasis on alternatives to case-control design [Towgood, Meuwese, Gilbert, Turner, \& Burgess, 2009]. However, it is interesting to note that the increased response variability in the ASD group was much higher than controls only for the neutral burlap texture, suggesting that ratings are less consistent for the ASD group when the perceptual attributes of a stimulus are more ambiguous. The idea that the ASD group is challenged by evaluating neutral or ambiguous stimuli is also supported by group differences in the correlations between perceived roughness and pleasantness. While this relation was consistently high and significant for both groups, it was significantly higher for ASD than control for the burlap texture. This suggests that for an affectively neutral stimulus, adults with ASD depend more heavily on the sensory aspects of the stimulus to determine their affective ratings than controls. This could be interpreted as an overly "literal" understanding of the relation between sensory and affective qualities of a more ambiguous stimulus by the ASD group.

We also noted session effects in the psychophysical portion of the study, generally consistent with recent work illustrating effects of prior exposure on affective ratings of touch [Löken, Evert, \& Wessberg, 2011]. The pattern of results we observed were that pleasant textures stay the same or improve slightly with repetition, while the perception of unpleasantness or roughness of the mesh texture tended to get worse with repeated exposure. Figure 2 suggests that the latter effect was especially true for the ASD group, while the former effect was weaker for ASD than controls. The phenomenon of stimulus satiation for pleasant stimuli is described in the gustatory system [Hetherington, Pirie, \& Nabb, 2002], and it is possible that a similar ceiling effect occurred across sessions with the brush stimulus. Likewise, anticipatory effects for the less pleasant stimuli after prior exposure may have resulted in lower pleasantness ratings for the other textures, particularly for the ASD group, for whom increased anxiety has been found to relate strongly anticipation, sensory stimuli, and unpleasant events [Gillott, \& Standen, 2007].

Although the group differences in the psychophysical responses to textures with a range of previously established roughness and pleasantness were subtle, we noted significant differences in the patterns of neural response in relevant areas of somatosensory and sensory integration cortex. While the control group showed significant increases in BOLD response to all three textures relative to rest, the ASD group showed a much less extensive pattern of response. The network activated in controls reflects primary and higher order somatosensory processing regions in the parietal lobe, such as the inferior parietal lobule, which is involved in somatosensory discrimination of objects [Reed et al., 2005] and vibrotactile frequency [Soros et al., 2007], and is heavily involved in multisensory integration [Mesulam et al., 1977] that is critical for the development of social and communication skills [Macaluso et al., 2004]. In addition, frontal areas such as the inferior frontal gyrus have been implicated in attention to tactile stimuli [Hagen et al., 2002], haptic perception and multisensory integration of texture stimuli [Sathian et al., 2011], as well as perception of socially relevant information such as facial expression [Bastiaansen et al., 2011] and general stimulus evaluation [Downar et al., 2002].

The integration of somatic information with social perception in these regions may be important for the ability to map another's body surface onto one's own and to use this mapping to interpret the meaning of others' actions, a significant deficit in ASD [Williams, 2008]. Recently, the inferior frontal gyrus and inferior parietal lobule were both implicated in the visual and tactile perception of facial expressions [Kitada et al., 2010], suggesting that these regions work together to support processing of socially relevant stimuli across sensory modalities. For the control group, the pattern of activation across these association areas was more extensive for pleasant and neutral textures than for the unpleasant mesh texture. 
In contrast, the ASD group did not exhibit as widespread a pattern of activation beyond early somatosensory areas, and for the neutral texture did not exhibit any response at our a priori-determined threshold. Interestingly, while the control group had the most extensive activation for the pleasant brush texture, the ASD group's most extensive pattern was for the unpleasant mesh texture; and in addition to contralateral SI and ipsilateral SII, included the inferior parietal lobule, suggesting increased attention to the unpleasant stimulation, and the insula, a region known for its role in evaluating somatosensory stimuli for their affective significance [Augustine, 1996, Kulkarni et al., 2005, McCabe et al., 2008].

Group contrasts confirmed that the ASD response to all three textures was diminished compared to the control group. The control group had more signal increase than the ASD group in overlapping networks of regions including ipsilateral SI, bilateral MFG, and inferior parietal lobule for all three textures. The MFG has an established role in the experience [Prohovnik et al. 2004] and perception of emotions [Sabatinelli et al., 2011], and may have been involved in the affective response to the stimulation. The IFG is involved in maintaining and updating internal representations of bodily state and the skin's surface [Spitoni, Galati, Antonucci, Haggard, \& Pizzamiglio, 2010; Wolpert, Goodbody, \& Husain, 1998]. Since these regions were less active in the ASD group for all three textures, it is likely that the neural representation of their affective valence and/or their effects on bodily state is atypical in ASD. For the more emotionally salient textures, brush and mesh, the cingulate cortex, a region involved in evaluating the affective significance of stimuli in preparation for action, was also more responsive in the control group. This finding in the anterior cingulate mirrors the results of Lindgren et al. [2012] who noted subgenual anterior cingulate activity in response to pleasant stroking touch.

For the most pleasant texture, the control group also exhibited a higher signal increase in the STG, a region that is important for assessing the social relevance of stimuli across sensory modalities [Pelphrey, Adolphs, \& Morris, 2004; Robins, Hunyadi, \& Schultz, 2009]. A recent study by Gordon et al. [2011] using similar gentle touch stimuli highlighted the superior temporal region as a multimodal node in the neural system for assessing social stimuli, including touch. This study also demonstrated responses in posterior insula and cingulate, findings with which our results are consistent. This suggests that the pleasant touch administered by the experimenter, an approximation of the gentle stroking touch that is characteristic of the CT afferent system, may have been differentially perceived as a socially relevant stimulus by the control group relative to the ASD group.

In group contrasts, the clusters in which the ASD response exceeded that of controls were less numerous for all the three textures, and absent entirely for the burlap texture. For the unpleasant mesh texture, regions that were more active in ASD than control included right inferior parietal lobule as well as the insular cortex, suggesting increased neural resources devoted to attending to and evaluating the affective significance of these negative stimuli relative to the control group. This relative over-representation of unpleasant and underrepresentation of pleasant textures in the brain may constitute a neural mechanism for tactile defensiveness in ASD. The insula has reciprocal connections to multiple sensory and limbic regions (for a thorough review, see Nieuwenhuys, 2012] and plays an important role in integrating internal and external cues to monitor the affective state of self and others [Decety \& Chaminade, 2003; Ruby \& Decety, 2004]. Further study of aberrant response in the insula may therefore shed light on its role within the neural networks that underlie complex social deficits that characterize ASD, such as empathy and emotion recognition.

These results suggest that individuals with ASD process affective touch stimuli differently than individuals without ASD. In general, they exhibit less response to stroked textures in classical somatosensory areas, including primary and secondary somatosensory cortex, as 
well as higher order somatosensory association areas located nearby the parietal and frontal regions. The neural representations that the ASD group did exhibit are most extensive for negative stimuli, and these unpleasant stimuli differentially recruited regions involved in evaluating emotional salience of somatosensory stimuli. Taken together, these data support the idea that the brain in people with ASD is hyporesponsive to pleasant tactile stimulation, and may be biased toward relative hyperresponsiveness to unpleasant tactile stimulation. It is possible that this imbalance gives rise to aberrant sensory responsiveness patterns that are linked with core symptoms of the disorder [Boyd et al., 2010; Foss-Feig, Heacock, \& Cascio, 2012; Lane et al., 2010; Watson et al., 2011], although the specific association of sensory responsiveness patterns and core features is itself still under investigation. The observed differential neural signature based on stimulus type in the ASD group may also provide some clues about the behavioral copresentation of both hyper- and hyporesponsiveness to different stimuli within the same individual, a paradox that is prominent in phenomenological accounts of sensory responsiveness in ASD.

We found a preliminary support for this in the significant correlation between BOLD response in the insula during stimulation with the mesh and burlap textures and social and repetitive behavior deficits as measured by the ADI-R. It should be noted that the correlation coefficients were fairly modest, and $P$ values were not corrected for multiple comparisons. This preliminary evidence, however, raises the possibility that aberrant neural responses to simple sensory stimuli are tied to the social and repetitive behavior abnormalities seen in ASD, the complexities of which are laid upon a much more basic foundation of affective response (rewarding or punishing) to sensory stimulation. Future studies should target the developmental course of affective responses to touch in the context of early social development in infants at risk for ASD.

Because our sample consisted of adults with ASD, we do not know the developmental time course of this aberrant neural signature in response to touch. An accurate representation of the bodily surface develops in the first few years of life [Brownell, Nichols, Svetlova, Zerwas, \& Ramani, 2010], and is important for social and cognitive abilities that necessitate differentiation of self from other [Schütz-Bosbach, Mancini, Aglioti, \& Haggard, 2006] and comparisons between self and other [Meltzoff, 2007], which may be precursors to more complex social skills such as understanding others as intentional agents [Gallese, 2003], and making inferences about others' emotions, experiences, or intentions. These skills are among those impacted by the social deficits that define ASD. Further study of the impact of altered touch perception between the ages of two and three, when explicit topographic representation of the bodily surface emerges, [Brownell et al., 2010] will provide important clues to how touch perception is linked to social behavior during development.

It was somewhat surprising to find such different neural response patterns in light of the similar perceptual reports of perceived pleasantness and roughness of the textures between the two groups. It is possible that the single stimulation in the psychophysical task was evaluated differently than the affective properties of the repeated stimulation in the scanner. It is also possible that the variability in the ASD pleasantness and roughness judgments obscured differences that might have been significant in a larger and/or less variable sample. Given the high IQ of our ASD sample and the straightforward nature of visual analog scale ratings, we do not attribute this discrepancy to impaired comprehension of the psychophysical task instructions. A limitation of our approach was the use of manual rather than automated brushing, which likely introduced variability in stimulation. Future work will replicate this study using an automated stimulator that will allow more complete control of speed and force of stimulation. 


\section{Conclusions}

This is the first study using fMRI to investigate responses to touch in ASD. We find evidence for diminished response to textures in a network of parietal somatosensory and association areas, extending to limbic and association areas in the frontal and temporal lobes. The most striking differences are to pleasant and neutral textures, while unpleasant textures have a relatively more complete representation in the ASD group, including some regions (SII, insula, IPL) that are hyperresponsive relative to controls. Future studies should be targeted toward (a) reconciling strikingly different neural response patterns and the largely similar self-reported affective judgments of textured stimuli; (b) characterizing neural responses to more directly social versus nonsocial tactile stimulation; as well as addressing (c) individual differences; and (d) the neural signatures of touch in younger samples. The early development of the somatosensory system [Lecanuet \& Schaal, 2002] and predictive value of tactile responsiveness in infants for later development of ASD [Baranek, 1999] make neural differences in somatosensory responses a promising candidate for an early biomarker for a subgroup of individuals with ASD.

\section{Acknowledgments}

This work was supported by Autism Speaks (\#2082 awarded to G.K.E). The authors wish to thank Rachael Wachter, Abigail Carroll-Sharpe, Ryan Allred, Thomas Pardue, and John Bulluck for assistance with data collection and management, as well as the participants who generously shared their time and effort for this study.

Grant sponsor: Autism Speaks

\section{References}

American Psychiatric Association. Dsm iv-tr. Diagnostic and statistical manual of mental disorders. 4. Washington, D.C: APA Press; 2000. text revision

Augustine JR. Circuitry and functional aspects of the insular lobe in primates including humans. Brain Res Brain Res Rev. 1996; 22:229-244. [PubMed: 8957561]

Baranek GT. Autism during infancy: a retrospective video analysis of sensory-motor and social behaviors at 9-12 months of age. Journal of Autism and Developmental Disorders. 1999; 29:213224. [PubMed: 10425584]

Baranek GT, David FJ, Poe MD, Stone WL, Watson LR. Sensory Experiences Questionnaire: discriminating sensory features in young children with autism, developmental delays, and typical development. Journal of Child Psychology and Psychiatry, and Allied Disciplines. 2006; 47:591601.

Bastiaansen JA, Thioux M, Nanetti L, van der Gaag C, Ketelaars C, Minderaa R, Keysers C. Agerelated increase in inferior frontal gyrus activity and social functioning in autism spectrum disorder. Biological Psychiatry. 69:832-838. [PubMed: 21310395]

Ben-Sasson A, Cermak SA, Orsmond GI, Tager-Flusberg H, Kadlec MB, Carter AS. Sensory clusters of toddlers with autism spectrum disorders: differences in affective symptoms. Journal of Child Psychology and Psychiatry, and Allied Disciplines. 2008; 29:817-825.

Blakemore SJ, Tavassoli T, Calo S, Thomas RM, Catmur C, et al. Tactile sensitivity in Asperger syndrome. Brain and Cognition. 2006; 61:5-13. [PubMed: 16500009]

Boyd BA, Baranek GT, Sideris J, Poe MD, Watson LR, et al. Sensory features and repetitive behaviors in children with autism and developmental delays. Autism Research. 2010; 3:78-87. [PubMed: 20437603]

Brett, M.; Anton, J-L.; Valabregue, R.; Poline, J-B. Region of interest analysis using an SPM toolbox [abstract]. Presented at the 8th International Conference on Functional Mapping of the Human Brain; Sendai, Japan. 2002.

Brownell CA, Nichols SR, Svetlova M, Zerwas S, Ramani G. The head bone's connected to the neck bone: when do toddlers represent their own body topography? Child Development. 2010; 81:797810. [PubMed: 20573105] 
Cascio C, McGlone F, Folger S, Tannan V, Baranek G, et al. Tactile perception in adults with autism: a multidimensional psychophysical study. Journal of Autism and Developmental Disorders. 2008; 38:127-137. [PubMed: 17415630]

Coskun MA, Varghese L, Reddoch S, Castillo EM, Pearson DA, Loveland KA, Papnicolaou AC, Sheth BR. How somatic cortical maps differ in autistic and typical brains. Neuroreport. 2009; 20:175-179. [PubMed: 19057419]

Damiano, CD.; Stone, WL.; Catania, EH.; Woodburn, K.; Warren, ZF., et al. Orientation to social and non-social sensory stimuli in infant siblings of children with autism spectrum disorders. Presented at the 10th Annual International Meeting for Autism Research; San Diego. 2011. p. 134.123

Dawson G, Watling R. Interventions to facilitate auditory, visual, and motor integration in autism: a review of the evidence. Journal of Autism and Developmental Disorders. 2000; 30:415-421. [PubMed: 11098877]

Decety J, Chaminade T. Neural correlates of feeling sympathy. Neuropsychologia. 2003; 41:127-138. [PubMed: 12459211]

Diedrichsen J, Shadmehr R. Detecting and adjusting for artifacts in fMRI time series data. Neuroimage. 2005; 27:624-634. [PubMed: 15975828]

Downar J, Crawley AP, Mikulis DJ, Davis KD. A cortical network sensitive to stimulus salience in a neutral behavioral context across multiple sensory modalities. J Neurophysiology. 2002; 87:615620.

Essick GK, McGlone F, Dancer C, Fabricant D, Ragin Y, et al. Quantitative assessment of pleasant touch. Neuroscience and Biobehavioral Reviews. 2010; 34:192-203. [PubMed: 19896001]

Field, T. Touch. Cambridge MA: MIT Press; 2001.

Foss-Feig JH, Heacock JL, Cascio CJ. Tactile responsiveness patterns and their association with core features in autism spectrum disorders. Research in Autism Spectrum Disorders. 2012; 6:337-344. [PubMed: 22059092]

Gallese V. The roots of empathy: The shared manifold hypothesis and the neural basis of intersubjectivity. Psychopathology. 2003; 36:171-180. [PubMed: 14504450]

Gillott A, Standen PJ. Levels of anxiety and sources of stress in adults with autism. Journal of Intellectual Disabilities. 2007; 11:359-370. [PubMed: 18029412]

Gordon I, Voos A, Bennett RH, Bolling DZ, Pelphrey KA, Kaiser MD. Brain mechanisms for processing affective touch. Human Brain Mapping. 2011 Nov 29. [Epub ahead of print]. 10.1002/ hbm. 21480

Güçlü B, Tanidir C, Mukaddes NM, Unal F. Tactile sensitivity of normal and autistic children. Somatosensory and Motor Research. 2007; 24:21-33. [PubMed: 17558920]

Guest S, Essick G, Dessirier JM, Blot K, Lopetcharat K, McGlone F. Sensory and affective judgments of skin during inter-and intrapersonal touch. Acta Psychologica. 2009; 130:115-126. [PubMed: 19059581]

Guest S, Dessirier JM, Mehrabyan A, McGLone F, Essick G, et al. The development and validation of sensory and emotional scales of touch perception. Attention, Perception, \& Psychophysics. 2011; 73:531-550.

Hagen MC, Zald DH, Thornton TA, Pardo JV. Somatosensory processing in the human inferior prefrontal cortex. Journal of Neurophysiology. 2002; 88:1400-1406. [PubMed: 12205161]

Happe F, Ronald A, Plomin R. Time to give up on a single explanation for autism. Nature Neuroscience. 2006; 9:1218-1220.

Harlow HF, Harlow MK. The effect of rearing conditions on behavior. Bulletin of the Menninger Clinic. 1962; 26:213-224. [PubMed: 13904733]

Hertenstein MJ, Verkamp JM, Kerestes AM, Homes RM. The communicative function of touch in humans, nonhuman primates, and rats: A review and synthesis of the empirical research. Genetic, Social, and General Psychology Monographs. 2006; 132:5-94.

Hetherington MM, Pirie LM, Nabb S. Stimulus satiation: Effects of repeated exposure to foods on pleasantness and intake. Appetite. 2002; 38:19-28. [PubMed: 11883914]

Hilton CL, Harper JD, Kueker RH, Lang AR, Abbacchi AM, et al. Sensory responsiveness as a predictor of social severity in children with high functioning autism spectrum disorders. Journal of Autism and Developmental Disorders. 2010; 40:937-945. [PubMed: 20108030] 
Jones R, Quigney C, Huws J. First-hand accounts of sensory perceptual experiences in autism: A qualitative analysis. Journal of Intellectual and Developmental Disability. 2003; 28:112-121.

Kanner L. Autistic disturbances of affective contact. The Nervous Child. 1943; 2:217-250.

Kientz MA, Dunn W. A comparison of the performance of children with and without autism on the Sensory Profile. The American Journal of Occupational Therapy. 1997; 51:530-537. [PubMed: 9242859]

Kitada R, Johnsrude IS, Kochiyama T, Lederman SJ. Brain networks involved in haptic and visual identification of facial expressions of emotion: an fMRI study. Neuroimage. 2010; 49:1677-1689. [PubMed: 19770059]

Kulkarni B, Bentley DE, Elliott R, Youell P, Watson A, et al. Attention to pain localization and unpleasantness discriminates the functions of the medial and lateral pain systems. The European Journal of Neuroscience. 2005; 21:3133-3142. [PubMed: 15978022]

Lancaster JL, Rainey LH, Summerlin JL, Freitas CS, Fox PT, et al. Automated labeling of the human brain: A preliminary report on the development and evaluation of a forward-transform method. Human Brain Mapping. 1997; 5:238-242. [PubMed: 20408222]

Lancaster JL, Woldorff MG, Parson LM, Liotti M, Freitas CS, et al. Automated Talairach atlas labels for functional brain mapping. Human Brain Mapping. 2000; 10:120-131. [PubMed: 10912591]

Lane AE, Young RL, Baker AE, Angley MT. Sensory processing subtypes in autism: Association with adaptive behavior. Journal of Autism and Developmental Disorders. 2010; 40:112-122. [PubMed: 19644746]

Lecanuet JP, Schaal B. Sensory performances in the human fœtus: A brief summary of research. Intellectica. 2002; 34:29-56.

LeCouteur, A.; Lord, C.; Rutter, M. The Autism Diagnostic Interview-Revised (ADI-R). Los Angeles: Western Psychological Corporation; 2003.

Lieberman MD, Cunningham WA. Type I and Type II error concerns in fMRI research: Re-balancing the scale. Social Cognitive and Affective Neuroscience. 2009; 4:423-428. [PubMed: 20035017]

Lindgren L, Westling G, Brulin C, Lehtipalo S, Andersson M, Nyberg L. Pleasant human touch is represented in pregenual anterior cingulate cortex. Neuroimage. 2012 Nov 10.59:3424-3432. [Epub ahead of print].

Löken LS, Evert M, Wessberg J. Pleasantness of touch in human glabrous and hairy skin: Order effects on affective ratings. Brain Research. 2011; 1417:9-15. [PubMed: 21907328]

Löken LS, Wessberg J, Morrison I, McGlone F, Olausson H. Coding of pleasant touch by unmyelinated afferents in humans. Nature Neuroscience. 2009; 12:547-548.

Lord, C.; Rutter, M.; DiLavore, P.; Risi, S. The autism diagnostic observation schedule (ados). Los Angeles: Western Psychological Corporation; 1999.

Macaluso E, George N, Dolan R, Spence C, Driver J. Spatial and temporal factors during processing of audiovisual speech: a PET study. Neuroimage. 2004; 21:725-732. [PubMed: 14980575]

Main M, Stadtman J. Infant response to rejection of physical contact by the mother: Aggression, avoidance, and conflict. Journal of the American Academy of Child Psychiatry. 1981; 20:292-307. [PubMed: 7264108]

McCabe C, Rolls ET, Bilderbeck A, McGlone F. Cognitive influences on the affective representation of touch and the sight of touch in the human brain. Social Cognitive and Affective Neuroscience. 2008; 3:97-108. [PubMed: 19015100]

McGlone F, Vallbo AB, Olausson H, Loke L, Wessberg J. Discriminative touch and emotional touch. Canadian Journal of Experimental Psychology. 2007; 61:171-183.

Meltzoff AN. "Like me": A foundation for social cognition. Developmental Science. 2007; 10:126134. [PubMed: 17181710]

Mesulam MM, Van Hoesen GW, Pandya DN, Geschwind N. Limbic and sensory connections of the inferior parietal lobule (area PG in the rhesus monkey: a study with a new method for horseradish peroxidase histochemistry. Brain Research. 1977; 136:393-414. [PubMed: 411543]

Montagu, A. Touching: The human significance of the skin. New York: Perennial Library; 1986.

Morrison I, Löken LS, Olausson H. The skin as a social organ. Experimental brain research. Experimentelle Hirnforschung. Experimentation cerebrale. 2010; 204:305-314. 
Müller RA, Kleinhans N, Kemmotsu N, Pierce K, Courchesne E. Abnormal variability and distribution of functional maps in autism: An fMRI study of motor learning. The American Journal of Psychiatry. 2003; 160:1847-1862. [PubMed: 14514501]

Myers BJ. Mother-infant bonding: The status of the critical-period hypothesis. Developmental Review. 1984; 4:240-274.

Nieuwenhuys R. The insular cortex: A review. 2012

Olausson H, Cole J, Vallbo A, McGlone F, Elam M, et al. Unmyelinated tactile afferents have opposite effects on insular and somatosensory cortical processing. Neuroscience Letters. 2008; 436:128132. [PubMed: 18395979]

Olausson H, Lamarre Y, Backlund H, Morin C, Wallin BG, et al. Unmyelinated tactile afferents signal touch and project to insular cortex. Nature Neuroscience. 2002; 5:900-904.

Pelphrey K, Adolphs R, Morris JP. Neuroanatomical substrates of social cognition dysfunction in autism. Mental Retardation and Developmental Disabilities Research Reviews. 2004; 10:259-271. [PubMed: 15666336]

Prohovnik I, Skudlarski P, Fulbright RK, Gore JC, Wexler BE. Functional MRI changes before and after onset of reported emotions. Psychiatry Research. 2004; 132:239-250. [PubMed: 15664795]

Reed CL, Klatzky RL, Halgren E. What vs. where in touch: an fMRI study. Neuroimage. 2005; 25:718-726. [PubMed: 15808973]

Robins DL, Hunyadi E, Schultz RT. Superior temporal activation in response to dynamic audio-visual emotional cues. Brain and Cognition. 2009; 69:269-278. [PubMed: 18809234]

Rogers SJ. What are infant siblings teaching us about autism in infancy? Autism Research. 2009; 2:125-137. [PubMed: 19582867]

Rogers SJ, Hepburn S, Wehner E. Parent report of sensory symptoms in toddlers with autism and those with other developmental disorders. Journal of Autism and Developmental Disorders. 2003; 33:631-642. [PubMed: 14714932]

Ruby P, Decety J. How would you feel versus how do you think she would feel? A neuroimaging study of perspective-taking with social emotions. Journal of Cognitive Neuroscience. 2004; 16:988-999. [PubMed: 15298786]

Sabatinelli D, Fortune EE, Li Q, Siddiqui A, Krafft C, Oliver WT, Beck S, Jeffries J. Emotional perception: meta-analyses of face and natural scene processing. Neuroimage. 2011; 54:2524-2533. [PubMed: 20951215]

Sathian K, Lacey S, Stilla R, Gibson GO, Deshpande G, Hu X, Laconte S, Glielmi C. Dual pathways for haptic and visual perception of spatial and texture information. Neuroimage. 2011; 57:462475. [PubMed: 21575727]

Schütz-Bosbach S, Mancini B, Aglioti SM, Haggard P. Self and other in the human motor system. Current Biology. 2006; 16:1830-1834. [PubMed: 16979561]

Soros P, Marmurek J, Tam F, Baker N, Staines WR, Graham SJ. Functional MRI of working memory and selective attention in vibrotactile frequency discrimination. BMC Neuroscie. 2007; 8:48.

Spitoni GF, Galati G, Antonucci G, Haggard P, Pizzamiglio L. Two forms of touch perception in the human brain. Experimental brain research. Experimentelle Hirnforschung. Experimentation cerebrale. 2010; 207:185-195.

Talairach, J.; Tournoux, P. Coplanar stereotactic atlas of the human brain. New York: Thieme Medical Publishers; 1988.

Toal F, Daly EM, Page L, Deeley Q, Hallahan B, et al. Clinical and anatomical heterogeneity in autism spectrum disorders: A structural MRI study. Psychological Medicine. 2010; 40:1171-1181. [PubMed: 19891805]

Tomcheck SD, Dunn W. Sensory processing in children with and without autism: A comparison study using the short sensory profile. The American Journal of Occupational Therapy. 2007; 61:190_ 200. [PubMed: 17436841]

Tommerdahl M, Tannan V, Cascio CJ, Baranek GT, Whitsel BL. Vibrotactile adaptation fails to enhance spatial localization in adults with autism. Brain Research. 2007; 1154:116-123. [PubMed: 17498672] 
Towgood KJ, Meuwese JD, Gilbert SJ, Turner MS, Burgess PW. Advantages of the multiple case series approach to the study of autism spectrum disorder. Neuropsychologia. 2009; 47:2981-2988. [PubMed: 19580821]

Vallbo AB, Olausson H, Wessberg J. Unmyelinated afferents constitute a second system coding tactile stimuli of the human hairy skin. Journal of Neurophysiology. 1999; 81:2753-2763. [PubMed: 10368395]

Watson LR, Patten E, Baranek GT, Poe M, Boyd B, et al. Differential associations between sensory response patterns and language, social, and communication measures in children with autism or other developmental disabilities. Journal of Speech, Language, and Hearing Research. 2011; 54:1562-1576.

Wechsler, D. Wechsler Intelligence Scale for Children. 4. San Antonio, TX: The Psychological Corporation; 2003.

Weiss SJ, Wilson P, Hertenstein MJ, Campos RG. The tactile context of a mother's caregiving: Implications for attachment of low birth weight infants. Infant Behavior and Development. 2000; 23:91-111.

Williams JH. Self-other relations in social development and autism: multiple roles for mirror neurons and other brain bases. Autism Research. 2008; 1:73-90. [PubMed: 19360654]

Wolpert DM, Goodbody SJ, Husain M. Maintaining internal representations: The role of the human superior parietal lobe. Nature Neuroscience. 1988; 1:529-533. 


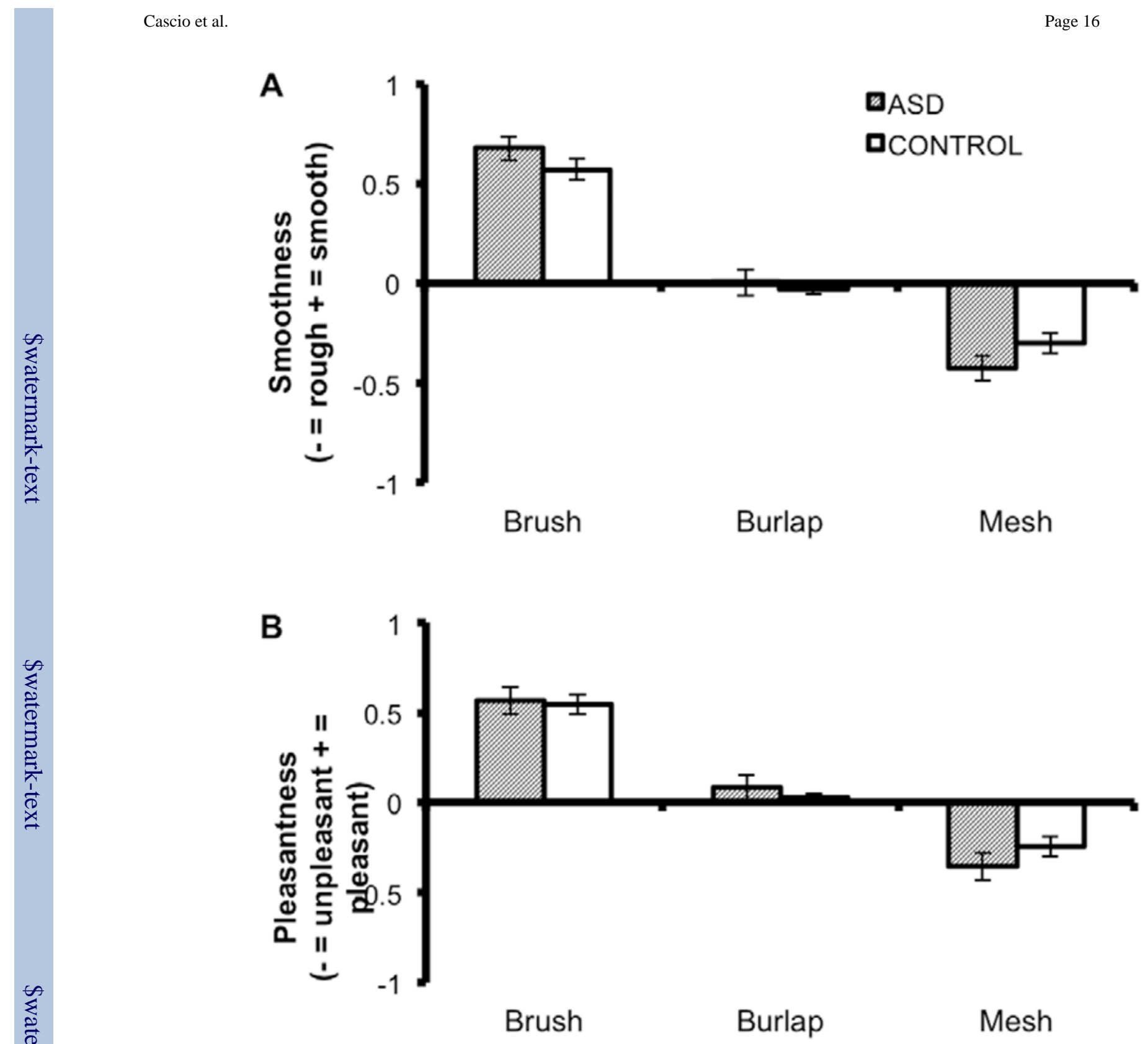

Figure 1.

Mean ratings on visual analogue scale (range: -1 to +1$)$ for $(\mathbf{A})$ roughness and $(\mathbf{B})$ pleasantness of the three textures for ASD (filled bars) and control (open bars) groups. 
A

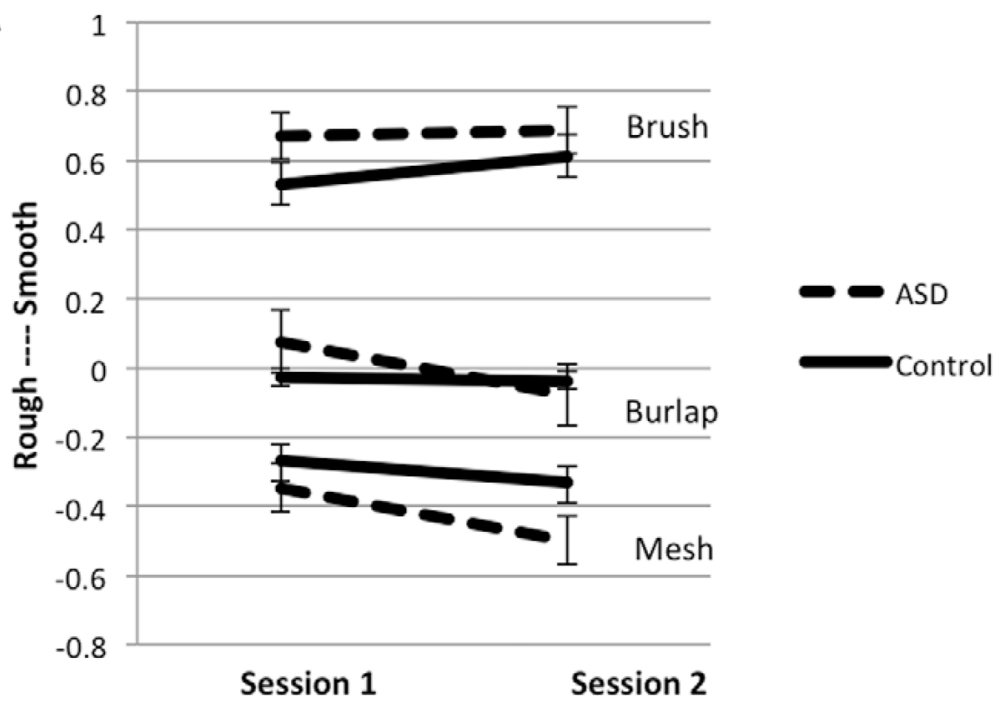

B

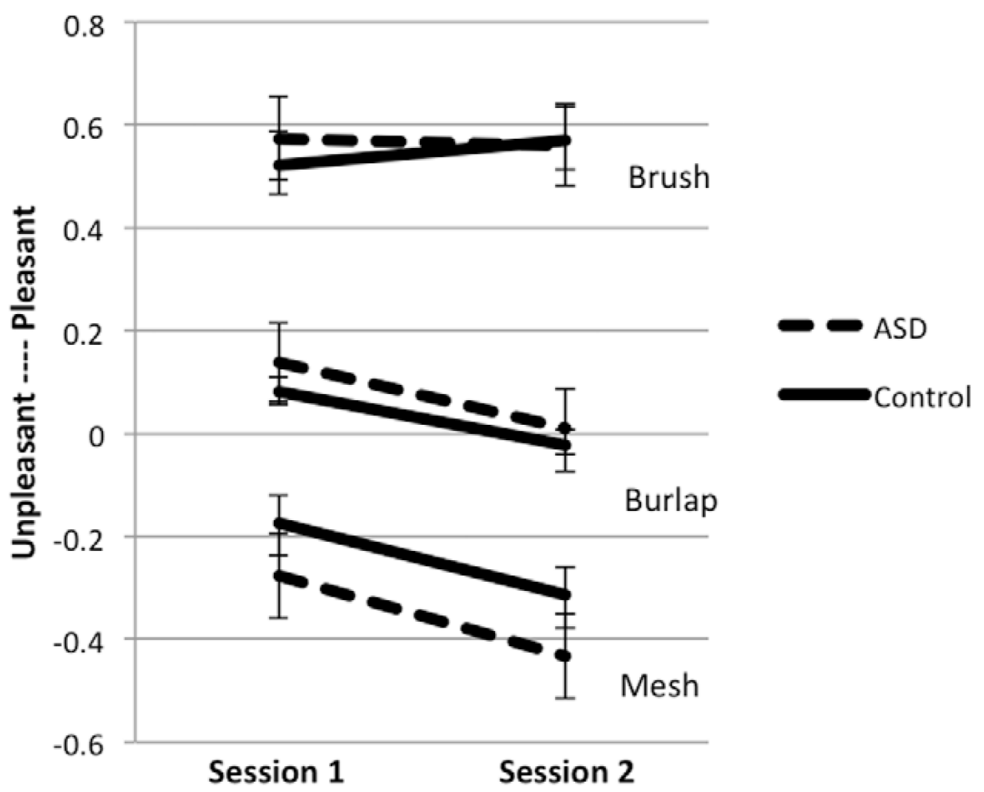

Figure 2.

Mean ratings on visual analogue scale (range: -1 to +1 ) for $(\mathbf{A})$ roughness and $(\mathbf{B})$ pleasantness for both groups, separated by session. 


\section{A. Control}

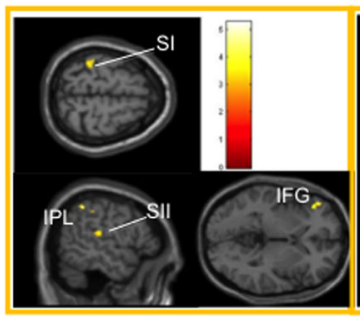

Brush - rest

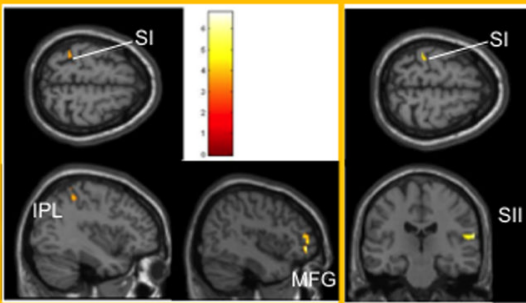

Burlap - rest

Mesh - rest

B. ASD

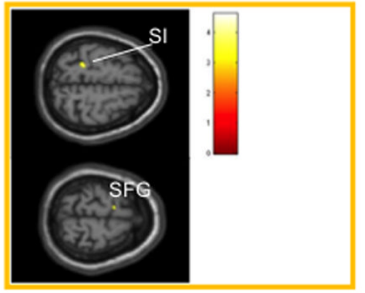

Brush - rest

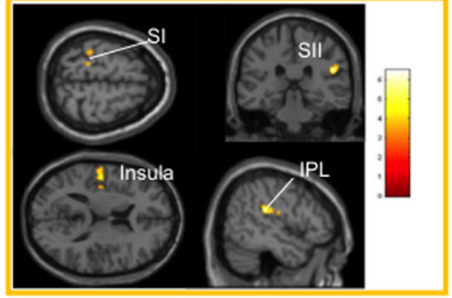

Mesh - rest

Figure 3 .

Statistical maps illustrating suprathreshold voxels for increased BOLD signal in response to the three textures in the one-sample $t$-tests for the (A) control group and (B) ASD group. Anatomical images are in neurological convention. SI: primary somatosensory cortex, SII: secondary somatosensory cortex, SFG: superior frontal gyrus, IPL: inferior parietal lobule, MFG: middle frontal gyrus, IFG: inferior frontal gyrus. 
A. Control > ASD

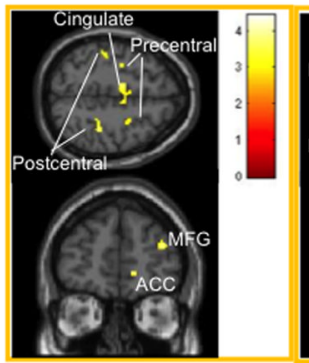

Brush

B. ASD > Control

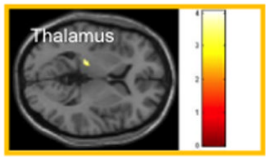

Brush

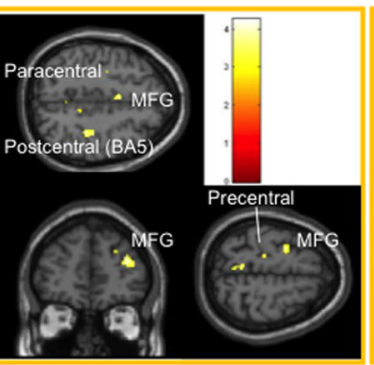

Burlap

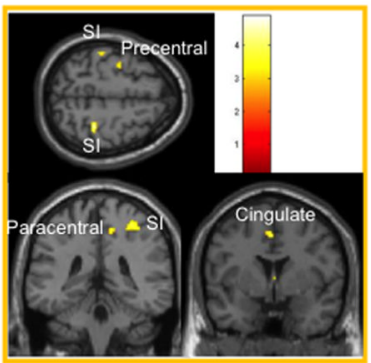

Mesh

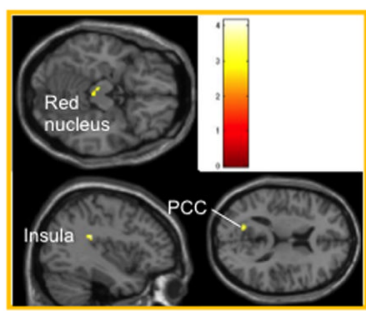

Mesh

Figure 4.

Statistical maps illustrating suprathreshold voxels for increased BOLD signal in response to the three textures in the two-sample $t$-tests for (A) Control > ASD and (B) ASD > Control. Anatomical images are in neurological convention. SI: Primary somatosensory cortex, MFG: Middle frontal gyrus, MedFG: Medial frontal gyrus, ACC: Anterior cingulate cortex, PCC: Posterior cingulate cortex. 


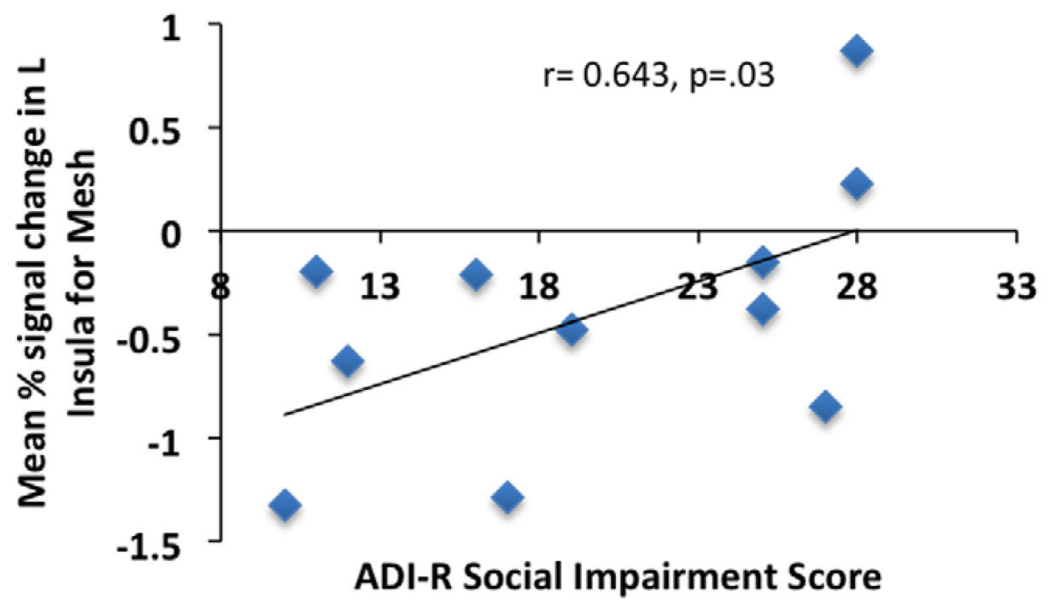

Figure 5.

Association between mean percent BOLD signal change in the $\mathrm{L}$ insula in response to stimulation with mesh in the ASD group and social impairment as measured by the ADI-R. 


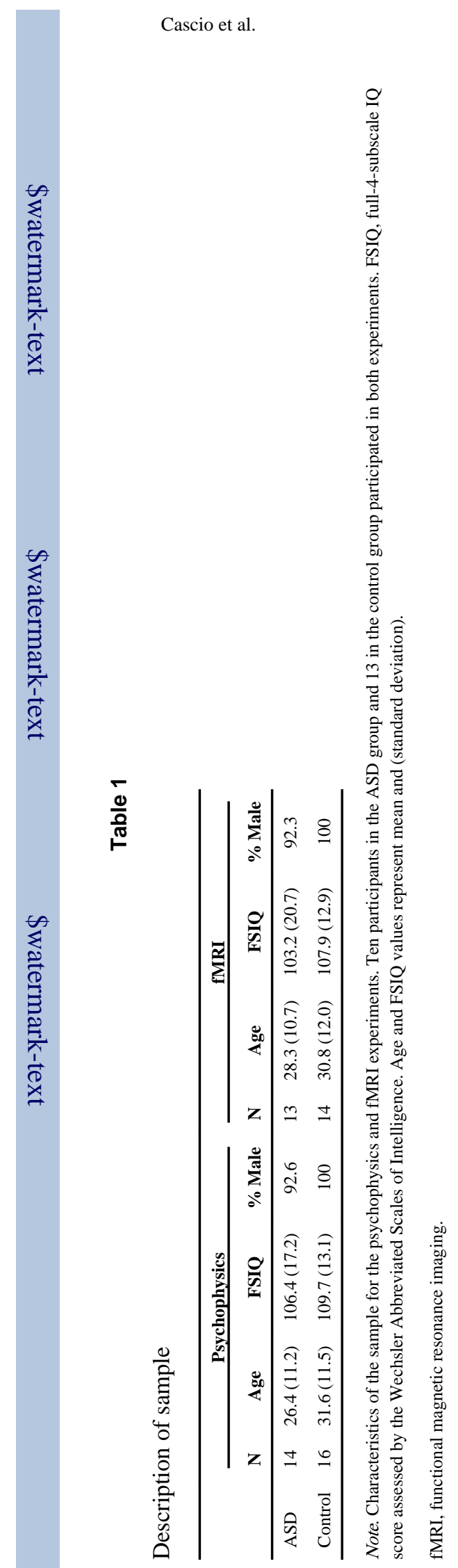

Autism Res. Author manuscript; available in PMC 2012 December 10. 
$\stackrel{N}{0}$

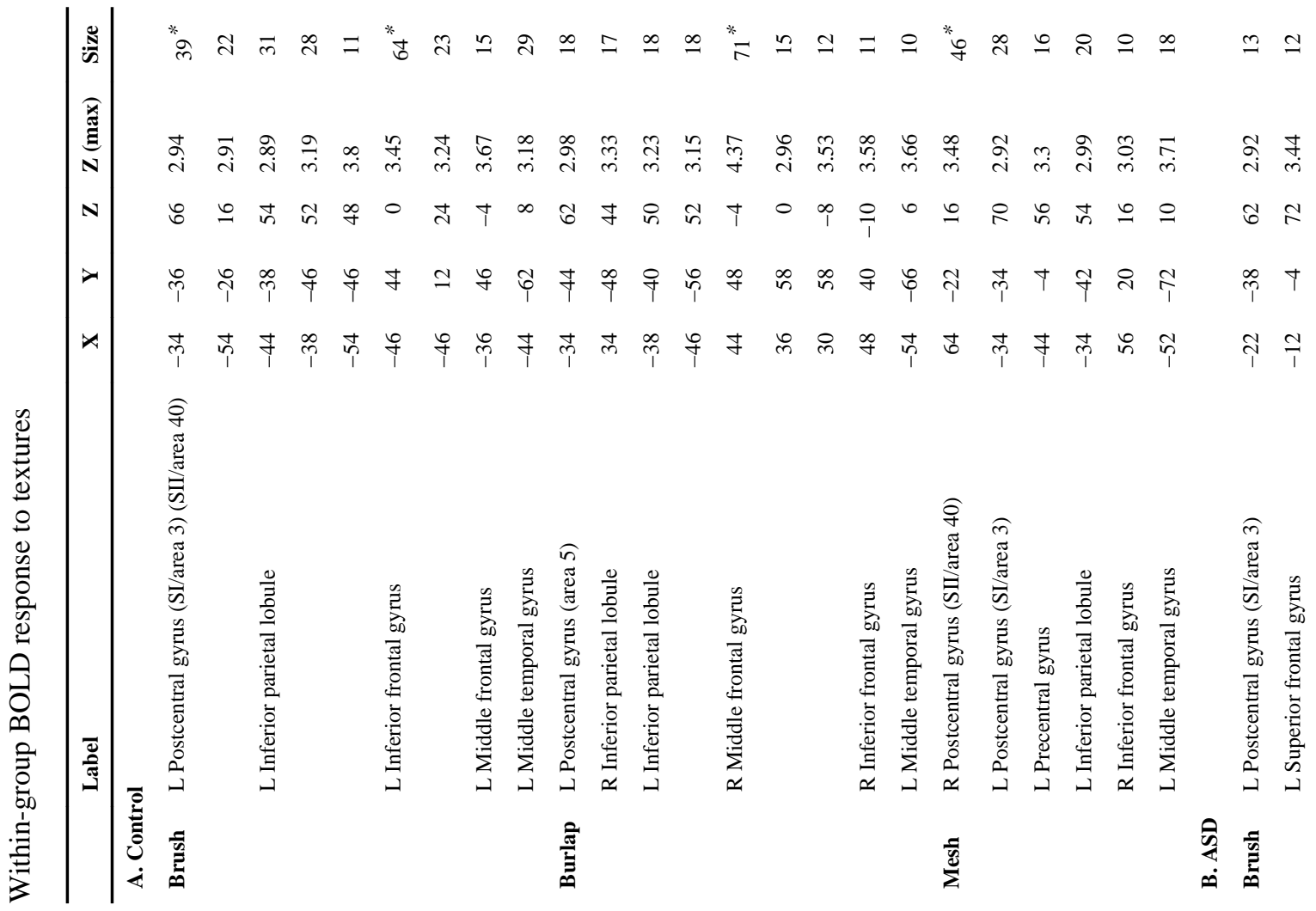




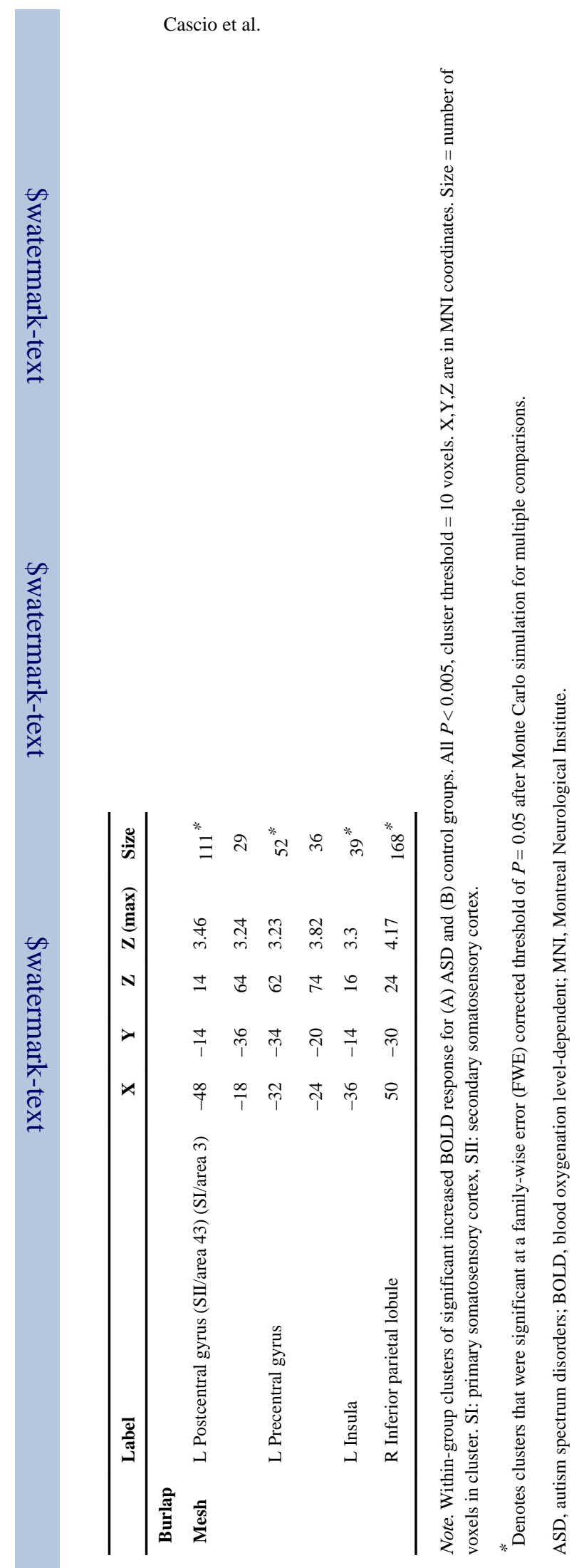

Autism Res. Author manuscript; available in PMC 2012 December 10. 


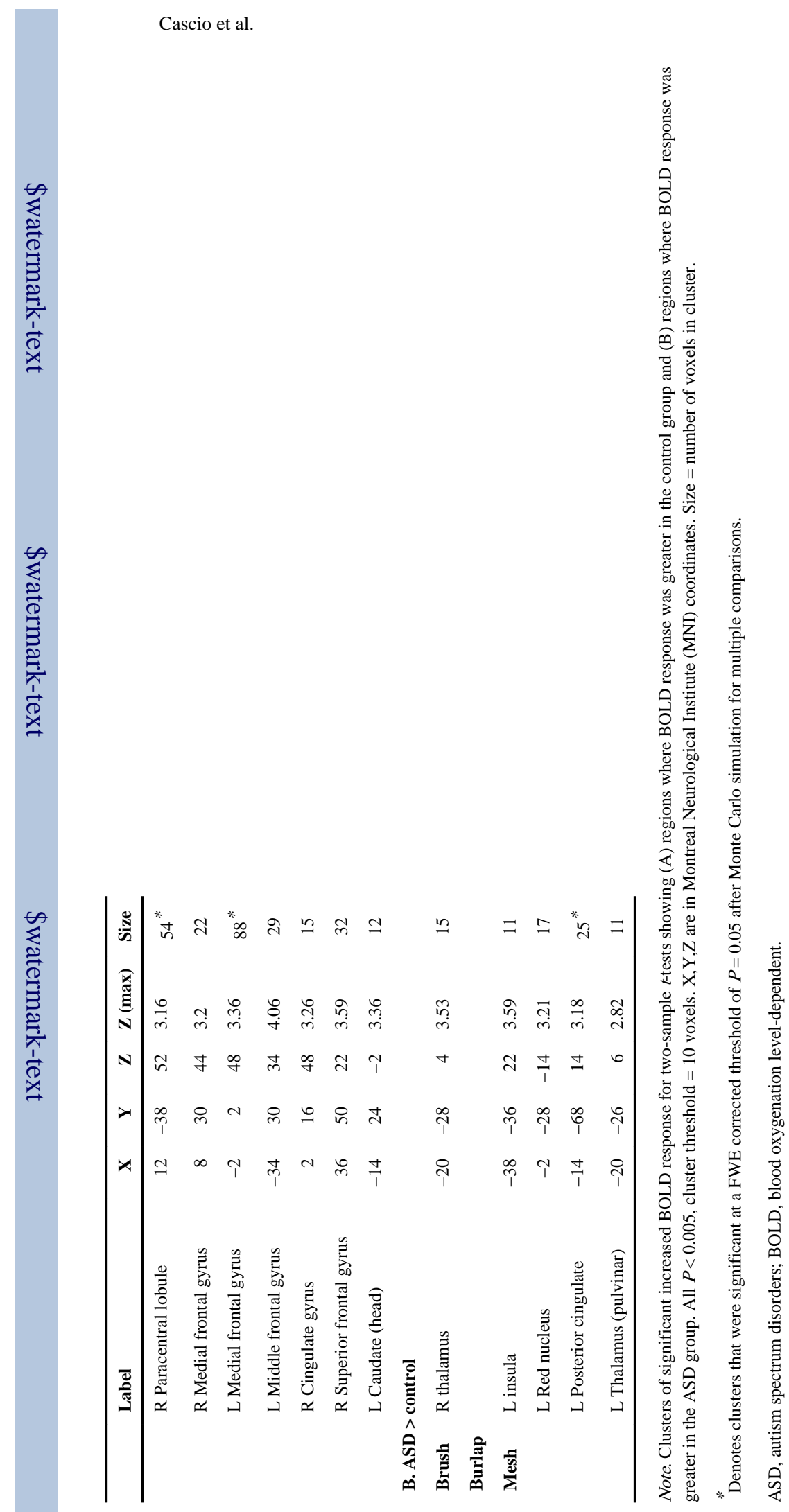

Page 25 